\title{
A ESCOLA PÚBLICA E A SOCIEDADE DEMOCRÁTICA: A CONTRIBUIÇÃO DE ANÍSIO TEIXEIRA
}

\author{
Patrícia Melo Magoga ${ }^{1}$ \\ Darcísio Natal Muraro ${ }^{2}$
}

\begin{abstract}
RESUMO: Este estudo objetiva refletir acerca do seguinte problema: qual é o papel da escola pública na formação da sociedade democrática? A pesquisa adota a metodologia bibliográfica, focando o estudo nas obras de Anísio Teixeira. O texto apresenta a contribuição do autor para a consolidação da escola pública brasileira. A educação proposta consiste na criação do ambiente democrático propiciado pelo ensino escolar. A sua vertente de escola nova concebe a educação como modo de vida democrático de reconstrução da experiência em torno de interesses comuns. Segundo Anísio, a escola pública é o instrumento institucional mais eficiente para a construção da sociedade democrática e, por isso, deve ser entendida e defendida necessariamente como universal, gratuita, obrigatória, laica e de qualidade.
\end{abstract}

Palavras-chave: Escola pública. Sociedade democrática. Educação. Participação social.

\section{THE PUBLIC SCHOOL AND THE DEMOCRATIC SOCIETY: ANÍSIO TEIXEIRA'S CONTRIBUTION}

\begin{abstract}
This study aims to reflect about the following issue: what is the role of the public school in the formation of a democratic society? The research adopts the bibliographic methodology, focusing the study on Anísio Teixeira's papers. The text presents the author's contribution to the consolidation of Brazilian public school. The proposed education consists of creating the democratic environment provided by school education. His new school perspective conceives education as a democratic way of life for the reconstruction of the experience around common interests. According to Anísio, the public school is the most efficient institutional instrument for the construction of a democratic society and, hence, must be understood and defended perforce as universal, gratuitous, mandatory, secular and high-grade.
\end{abstract}

Keywords: Public school. Democratic society. Education. Social participation.

\footnotetext{
*Este artigo está vinculado ao Projeto de Pesquisa cadastrado na Universidade Estadual de Londrina sob o título "A Educação Filosófica e a Política: A Comunidade Democrática como Espaço Público na Escola”. O artigo resulta de projeto de mestrado, tendo como agência de fomento a CAPES.

1.Universidade Estadual de Londrina - Programa de Pós-graduação em Educação - Londrina (PR), Brasil. E-mail: patricia_magoga@hotmail.com

2.Universidade Estadual de Londrina - Departamento de Educação -Programa de Pós-graduação em Educação - Londrina (PR), Brasil.E-mail: murarodnm@gmail.com
} 


\title{
LA ESCUELA PÚBLICA Y LA SOCIEDAD DEMOCRÁTICA: LA CONTRIBUCIÓN DE ANÍSIO TEIXEIRA
}

\begin{abstract}
RESUMEN: Este estudio tiene como objetivo reflexionar sobre el siguiente problema: ¿cuál es el papel de la escuela pública en la formación de una sociedad democrática? La investigación adopta la metodología bibliográfica, centrando el estudio en los trabajos de Anísio Teixeira. El texto presenta la contribución del autor a la consolidación de la escuela pública brasileña. La educación propuesta consiste en crear el ambiente democrático proporcionado por la educación escolar. Su nuevo aspecto escolar concibe la educación como una forma de vida democrática para la reconstrucción de la experiencia en torno a intereses comunes. Según Anísio, la escuela pública es el instrumento institucional más eficiente para la construcción de una sociedad democrática y, por lo tanto, debe entenderse y defenderse necesariamente como universal, gratuita, obligatoria, secular y de calidad.
\end{abstract}

Palabras-clave: Escuela pública. Sociedad democrática. Educación. Participación social.

\section{Introdução}

A escola pública, no contexto atual, passa por uma profunda crise, que se relaciona ao conflito de interesses entre a sua função de formadora do povo como soberano em uma sociedade democrática e a visão mercadológica de preparação das novas gerações para o mercado de trabalho. Essa tendência tem conquistado os espaços de poder e legitimado uma educação voltada para o aprendizado técnico, a serviço das demandas do mercado. Dessa maneira, a força político-comercial impõe, também, à esfera pública essa visão educacional, por meio de reformas que excluem a formação humanística e a transmissão da cultura. Assim, esse movimento mantém o sistema de classes e a defesa dos privilégios das elites, inclusive o privilégio do acesso a uma educação diferenciada para seus diletos membros, de acordo com seus interesses.

O enfrentamento desse conflito exige estudos que esclareçam o papel da escola pública e argumentem a favor do papel dela para o desenvolvimento da democracia. Nesse sentido, formulamos a problemática que nos orientará nesta reflexão: qual é o papel da escola pública na formação da sociedade democrática? A questão assim colocada, tendo em vista pensar o momento atual do ensino público no Brasil, remete-nos aos precedentes históricos de luta, levando em consideração a função social e democrática da educação. Por isso, nosso estudo se apoia no resgate do legado de Anísio Teixeira, que, tanto no plano teórico quanto, consequentemente, no prático, atuou na defesa da escola pública e democrática.

Para o desenvolvimento da discussão proposta, nossa pesquisa se baseia em uma análise conceitual das funções social, democrática e humanizadora da educação, a partir das bases do pensamento anisiano. Por se tratar de uma pesquisa bibliográfica, este estudo focará nas obras Educação no Brasil (1969), Educação Não é Privilégio (1971) e Pequena Introdução à Filosofia da Educação (2000), de Anísio Teixeira. Na medida em que for necessário elucidar conceitos, buscaremos referenciar o estudo na Filosofia da Educação de John Dewey, que embasa os trabalhos de Teixeira. Utilizaremos também o apoio de outros autores, como Azevedo et al. (2010), Geribello (1973), Nascimento (2009) e Nunes (2000).

É válido ressaltar, a princípio, que Teixeira deparou com a questão central do problema da educação nacional de seu tempo: é possível um sistema educativo ser dirigido por um Estado dominado por uma 
elite que busca manter seus privilégios e, ao mesmo tempo, manter a função social da educação? O autor tinha, diante de si, a contradição do sistema que, ao servir aos privilégios privados da classe dominante, defrontava-se com a defesa dos interesses públicos, voltados, portanto, a uma perspectiva democrática do acesso à educação.

Desse modo, o educador brasileiro estava certo sobre a mudança que se fazia necessária: conceber a educação como direito individual a ser assegurado pelo Estado. A mediação para operacionalizar esse princípio é a escola pública, que proporciona as bases para a integração e o desenvolvimento social, bem como para o próprio funcionamento do Estado democrático. Na concepção de Teixeira, a ênfase na integração social tem uma base antropológica: "Tanto o homem é um ser social, que nada o faz mais inumano do que essa falta de integração social, essa falta de uma sociedade inteiriça a que se possa servir e em que se possa apoiar" (2009, p. 50). Para o autor, a educação é um direito e a democracia não tolera privilégios.

Para além disso, Teixeira explica que a educação fundamenta a crença na democracia. No seu entendimento, tomando por base as ideias de John Dewey ${ }^{1}$ (1859-1952), cabe à educação o aprimoramento do conceito de democracia, reformulando continuamente seu significado de vida associada, haja vista que a educação é uma função cívica:

Uma sociedade é democrática na proporção em que prepara todos os seus membros para com igualdade aquinhoarem de seus benefícios e em que assegura o maleável reajustamento de suas instituições por meio da interação das diversas formas da vida associada. Essa sociedade deve adotar um tipo de educação que proporcione aos indivíduos um interesse pessoal nas relações e direções sociais, e hábitos de espírito que permitam mudanças sociais sem o ocasionamento de desordens (DEWEY, 1979, p. 106).

Teixeira, ao analisar o que o Brasil poderia fazer para transformar sua condição de país não democrático e desigual, percebeu que a educação era fator essencial para que isso pudesse aconteçer de modo intencional e consciente. Logo, a educação escolar poderia promover a emancipação social e econômica do país. Em tempo, observou que um dos problemas “[...] está na base de toda a descrença generalizada de economistas e homens práticos na eficácia da escola para o processo de desenvolvimento. E daí a resistência à distribuição dos recursos necessários para a aceleração do processo educativo" (TEIXEIRA, 1971, p. 137). Por isso, mesmo com o advento da República e com o início do Estado democrático, o país se manteve em uma condição de extrema segregação, com a evidente separação entre elites e servis. Sua concepção dessa realidade tinha bases na crítica de Dewey:

Não basta fazer-se que a educação não seja usada ativamente como instrumento para facilitar a exploração de uma classe por outra. Devem assegurar-se as facilidades escolares com tal amplitude e eficácia que, de fato, e não em nome somente, se diminuam os efeitos das desigualdades econômicas e se outorgue a todos os cidadãos a igualdade de preparo para suas futuras carreiras (DEWEY, 1979, p. 105).

O fato é que, para isso, cabe à administração pública proporcionar recursos para criar estrutura e oportunidade intelectual para todos, bem como repensar conteúdos e métodos tradicionais de ensino, de modo que todos em idade escolar estejam sob a influência de uma educação escolar democrática e reflexiva. Diante disso, Teixeira travou, no Brasil, a luta por um sistema universal de ensino que fosse público e comum a todos.

Em sua obra Educação não é privilégio, o educador traz as palavras de Horace Mann² (1796-1859), o qual, segundo ele, foi “[...] o grande batalhador da educação pública e universal, nos Estados Unidos da 
América [...]" (TEIXEIRA, 1971, p. 53). Esse texto faz menção à consciência que se deve formar para que uma sociedade seja verdadeiramente democrática, desenvolva-se e torne-se integrada socialmente:

\begin{abstract}
Nada por certo, salvo a educação universal, pode contrabalançar a tendência à dominação do capital e à servilidade do trabalho. Se uma classe possui toda a riqueza e toda a educação, enquanto o restante da sociedade é ignorante e pobre, pouco importa o nome que dermos à relação entre uns e outros: em verdade e de fato, os segundos serão os dependentes servis e subjugados dos primeiros. Mas, se a educação for difundida por igual, atrairá ela, com a mais forte de todas as forças, posses e bens, pois nunca aconteceu e nunca acontecerá que um corpo de homens inteligentes e práticos venha a se conservar permanentemente pobre. [...] A educação, portanto, mais do que qualquer outro instrumento de origem humana, é a grande igualadora das condições entre os homens - o eixo de equilíbrio da maquinaria social... Dá a cada homem a independência e os meios de resistir ao egoísmo dos outros homens. Faz mais do que desarmar os pobres da sua hostilidade para com os ricos: impede-os de ser pobres (TEIXEIRA, 1971, p. 54 apud MANN, 1848, p. 668-669).
\end{abstract}

Destarte, Teixeira buscou bases teóricas que lhe permitissem fundamentar sua defesa da educação pública, evidenciando que os serviços educacionais haveriam de ser, para a população e para o governo, parte dos serviços públicos de maior relevância. Na visão de Teixeira (1971), era dessa maneira que os problemas da rígida estratificação social e dos graves desníveis econômicos da sociedade brasileira poderiam ser enfrentados, visando à criação da igualdade de oportunidades conforme rege a essência do regime democrático.

\title{
A Contribuição de Teixeira para a Educação
}

A contextualização da trajetória de Teixeira na educação brasileira é importante para entendermos sua particiapação na análise do conceito de escola e no engendramento do sistema de ensino público do Brasil. Nunes (2000) relata que Teixeira nasceu em Caetité, no sertão da Bahia, e foi criado em um ambiente de elite. Era filho de um coronel nordestino, deputado e legislador municipal, muito bem-relacionado na região. Deocleciano Teixeira, pai de Anísio, via nele seu possível sucessor político.

Posteriormente, baseado na disciplina e na organização que aprendera na escola dos jesuítas em sua educação básica, bem como nos conhecimentos jurídicos adquiridos no curso superior de Direito, Anísio desenvolveu boa conversa com o governador Góes Calmon, para o qual seu pai fez campanha. Ao perceber suas disciplina e capacidade intelectual, Calmon, mesmo sabendo que Anísio não tinha especialidade nessa área, resolveu dar-lhe uma oportunidade, nomeando-o Inspetor-Geral do Ensino, sendo esse cargo, também, forma de agradecimento ao apoio de Deocleciano.

Como primeiro aconselhamento, o governador lhe sugeriu a leitura da obra Métodos Americanos de Educação (de 1927), de Omer Buyse ${ }^{3}$ (1865-1945). Foi estudando sobre sistemas educacionais dos países do Primeiro Mundo, inteirando-se sobre o funcionamento do ensino no Brasil e ouvindo os conselhos de colegas da área que Teixeira passou a compreender com mais profundidade os problemas do ensino público nacional.

Marcado por sua formação cultural intelectualista e motivado por sua dedicação em tudo que acreditava e com que se comprometia, iniciou seu legado reunindo representantes de todos os órgãos e instituições relacionadas à educação para discutir, analisar e buscar maneiras de aperfeiçoar o sistema de ensino público. Nunes (2000) relata que, nesse processo de conhecer a realidade do sistema de ensino, 
Teixeira deparou com a precariedade estrutural da educação pública baiana: escolas em prédios precários e sem mobília e material adequados para a atividade educacional. Os professores assumiam, com a sua própria renda, o aluguel e a manutenção desses prédios e os alunos levavam suas próprias mesas e cadeiras, quando não se sentavam no chão para participar das aulas. A autora complementa:

Anísio defrontava-se com a dispersão do serviço escolar, reduzido à alfabetização rudimentar, pelos diversos municípios; com a falta de seriedade administrativa e técnica; com a falta de escolas primárias públicas e de professores. Alimentava essa situação e, ao mesmo tempo, a agravava a subvenção a escolas particulares feita pelas prefeituras municipais. Essa prática persistia apesar de a primeira constituição estadual baiana [...] estabelecer [...] a gratuidade $\mathrm{e}$ a universalização do ensino primário (NUNES, 2000, p. 91).

Por conseguinte, Teixeira incentivou projetos de lei que propunham reformas na educação pública. Embora aprovados, os projetos foram muito criticados pela população, em especial pelos próprios professores. Foi um período difícil de mudanças, com resistência de alguns e admiração de outros. Teixeira enfrentou muitas críticas de diferentes frentes, tanto daqueles que o viam como comunista quanto dos que o julgavam fruto e defensor dos interesses da elite. No entanto, suas essência e luta foram além dessas dicotomia e polarização. O fato é que ele executou reformas em um período de visão fixa da sociedade, causando, assim, desconforto até pelas boas mudanças. Sempre muito aberto ao diálogo e ao debate, respondeu a essa resistência popular por meio do uso da palavra em encontros, audiências, jornais e revistas.

Satisfeito com o trabalho de Teixeira, em 1927, Calmon consegue aprovar uma bolsa de estudos para que o pesquisador fosse aos Estados Unidos entender o funcionamento da educação naquele país de Primeiro Mundo, que tinha uma visão progressiva e moderna da sociedade. Na Columbia University, em Nova York, Teixeira conheceu John Dewey no papel de professor emérito. Após retorno ao Brasil, passou a ser o grande propulsor das ideias de Dewey no país, além de se identificar com a filosofia pragmatista e progressiva da qual o filósofo americano foi um dos precursores. Segundo Nunes, Anísio “[...] valorizou o sistema de inspeção escolar norte-americano, concebido menos como fiscalização e mais como orientação pedagógica" (2000, p. 118). É essa a característica que ele resolve trazer para o Brasil, incorporando, assim, os profissionais da educação em sua luta.

Ao retornar ao Brasil, com uma nova base filosófica da educação progressista e de administração escolar, Teixeira buscou transformar o modelo de ensino tradicional no país. Esse trabalho consistiu no estímulo e na cobrança do envolvimento docente com o trabalho pedagógico, bem como na sistematização do sistema escolar público. O estudioso construiu, também, novas escolas e investiu na renovação das teorias pedagógicas com a participação dos professores. Nunes destaca:

Dessa forma, a exigência da disciplina docente era compensada por sinais visíveis que reforçavam o calor das convicções e criavam um clima de comunhão de responsabilidades, segundo o qual a tarefa educativa era assumida primordialmente como formação de consciência e pela qual a escola se afastava da casa e se aproximava das ruas (NUNES, 2000, p. 584).

Nesse ínterim, Teixeira foi se identificando cada vez mais com a educação, a ponto de definitivamente desistir da carreira clerical e da magistratura, incorporando a profissão de educador dentro do seu papel político em prol do ensino público nacional. Em tempo, foi um dos grandes gestores da educação como defensor da escola pública, gratuita, universal, laica e de qualidade. Propôs o rompimento com o sistema de ensino público tradicional e criou a rede municipal da escola primária. 
Teixeira foi compulsoriamente aposentado de sua cadeira na Faculdade de Filosofia da Universidade do Brasil pelo regime de exceção instaurado em 1964. Com o início da ditadura militar, viajou para atuar como professor visitante na Columbia University, em Nova York, e na University of Califórnia, em Los Angeles. Em 1971, foi encontrado morto no fundo do poço de um elevador. Entretanto, os fatos que ocasionaram sua morte não têm explicação conclusiva, tendo gerado investigações da Comissão da Verdade para buscar esclarecimentos ${ }^{4}$.

$\mathrm{Na}$ impossibilidade de um levantamento exaustivo de sua atuação no campo da educação, destacamos aqui alguns aspectos da trajetória de vida de Anísio Teixeira a fim de ressaltarmos sua atuação na luta pela educação pública como razão de vida.

\section{A Concepção de Escola para Teixeira}

Teixeira fez radical guinada em sua trajetória de vida intelectual e prática. Por ser filho de coronel, poderia ter direcionado sua vida para a defesa e a manutenção dos interesses das elites e de um sistema de poder que serve ao privilégio de classe. No entanto, o conhecimento da filosofia de John Dewey o incentivou na reconstrução do seu entendimento de uma sociedade democrática e da necessidade de fortalecer a educação pública. O estudioso queria mais do que levantar bandeira em um período crítico de evolução. Portanto, pesquisou e refletiu sobre os fins da educação para uma sociedade democrática, para então lutar pelo que acreditava; ou seja, por um programa completo de reconstrução educacional, atendendo às necessidades da época.

Desse modo, o grupo de estudiosos da educação do qual Teixeira fez parte percebeu a necessidade de analisar os aspectos filosóficos e sociais da educação, para além dos aspectos técnicos e metodológicos, pois entendia que faltava esse olhar sobre a resolução dos problemas da gestão escolar pública. Esses intelectuais nada mais queriam senão mostrar que a educação era também uma ciência que precisava ser desenvolvida como todas as outras; ou seja, a partir do estudo científico e experimental.

No novo perfil de sociedade que nasceu com o desenvolvimento da ciência experimental, a qual parte da compreensão de uma realidade em constante mudança, o contexto se transformou e os interesses se renovaram, motivo pelo qual as características da escola tradicional não se encaixavam mais. Tal modelo de educação atendia às necessidades quando a ideia principal era manter os velhos e bons costumes, propagar as verdades eternas passadas de geração em geração e manter tudo de acordo com a tradição.

Pimenta ressalta a crítica a esse modelo educacional trazendo as ideias deweyanas: “[...] para Dewey, em uma sociedade em que se espera que a maioria dos alunos não tenha objetivos ou ideias próprias e, por isso, receba as ordens dos detentores da autoridade, a servidão mental é necessária para disciplinar as massas" (PIMENTA, 2010, p. 67). Assim, a educação tradicional fazia o papel de manter tudo e todos ajustados ao modelo fixo de sociedade, visto que apenas ensinava algumas artes especializadas aos filhos dos burgueses e a alfabetização rudimentar aos mais desfavorecidos.

Além disso, com o desenvolvimento da ciência experimental e o consequente advento da industrialização, que trouxe a transformação da sociedade na civilização moderna, a constituição tradicional da família mudou. Os pais foram para o mercado de trabalho fora de casa, não sobrando, assim, muito tempo para a educação moral de seus filhos, papel que passou a ser atribuído à escola e somado à sua função propedêutica de ensinar artes e alfabetizar. Com isso, Teixeira analisa o modelo de escola a ser superado:

Antes a escola suplementava, com algumas informações dogmáticas, uma educação que o lar e a comunidade ministravam ao indivíduo, em uma ordem, por assim dizer, estática. Toda educação consistia em ensinar a seguir e a obedecer (TEIXEIRA, 2000, p. 36). 
Essa transformação trouxe mobilidade para a sociedade moderna, entendendo o futuro como algo incerto. Diante disso, não fazia mais sentido continuar educando o homem para um futuro desconhecido por meio de aspectos estagnados do passado. Com a sociedade em movimento, era necessária uma educação que acompanhasse o progresso, atendendo às novas demandas, o que já acontecia nos Estados Unidos e era chamado Educação Progressiva.

O fato é que essa mudança social passou a exigir novos moldes de educação, em contraste com aqueles da escola tradicional. Segundo Geribello, “[...] a escola não mais pode ser considerada apenas como órgão intencional de transmissão de cultura. Foi elevada à categoria de instituição fundamental da sociedade moderna" (1973, p. 139). A Revolução Francesa, fruto dessas mudanças, aconteceu com o intuito de exigir uma educação que possibilitasse ao indivíduo ser o que desejasse, independentemente de suas posições social e hierárquica, bem como de sua raça ou de seu patrimônio. O sujeito tinha, então, a oportunidade de ser, na sociedade, “[...] aquilo que seus dotes inatos, devidamente desenvolvidos, determinassem” (GERIBELLO, 1973, p. 92). À escola cabia direcionar o desenvolvimento dessas habilidades individuais. Nas palavras da autora:

[...] na Convenção revolucionária francesa formulou-se novo ideal de educação escolar: uma nova concepção de sociedade em que privilégios de classe, de dinheiro e de herança não existissem e em que o indivíduo pudesse buscar, pela escola, sua posição na vida social. Portanto, era uma educação escolar para todos, dentro de um espírito renovador da sociedade e não de universalização da escola existente (GERIBELLO, 1973, p. 92).

Entendendo que o método teórico da escola tradicional não formava o indivíduo para viver em comunidade de maneira efetiva, a escola nova propunha ensinar por meio da experiência. Teixeira afirma: "[...] aprender é adquirir um novo modo de agir" (GERIBELLO, 1973, p. 137). Para o autor, a nova educação concebe que é pelas vivências ajustadas à sua vida dentro e fora da escola que o ser humano aprende efetivamente, a tal ponto de incorporar as aprendizagens como novos hábitos de vida. Completa o educador:

A reorganização importa em nada menos do que trazer a vida para a escola. A escola deve vir a ser o lugar onde a criança venha a viver plena e integralmente. Só vivendo, a criança poderá ganhar os hábitos morais e sociais de que precisa, para ter uma vida feliz e integrada, em um meio dinâmico e flexível tal qual o de hoje (TEIXEIRA, 2000, p. 40).

Para complementar a reflexão sobre a concepção de escola, trazemos Fernando de Azevedo (1894$1974)^{5}$, que, com seu ponto de vista sociológico e também influenciado pelos fundamentos conceituais deweyanos, definiu a escola como parte do processo social que se transforma e se adapta ao meio. Portanto, a ela cabe ter uma consciência compreensiva que acolha a multiplicidade cultural.

Primeiramente, o sociólogo e educador brasileiro defendeu que a educação era a forma de entender a variação social e que, para tanto, ela precisava ser analisada de uma ótica em movimento e a partir do interesse de todos, não apenas de uma minoria dominante. Assim como Azevedo, Teixeira enxergou a escola como a formação do ser social na condição de parte integrante de um todo, com suas particularidades e habilidades individuais. O Manifesto dos pioneiros da Educação Nova (1932; AZEVEDO et al., 2010) veio para defender a escola como espaço social e definir o conceito e os fundamentos da nova escola. Segundo Azevedo et al.:

[...] a cada época, na marcha da civilização, correspondem processos novos de educação para uma adaptação constante às novas condições da vida social e à satisfação de suas tendências e de suas necessidades. As ideias e as instituições pedagógicas são essencialmente "o produto de realidades sociais e políticas" (2010, p. 25). 
Nesse sentido, Teixeira e demais pensadores da educação da sua geração foram os primeiros que, de algum modo, despertaram uma consciência educacional relacionada aos desenvolvimentos social e econômico. A partir daí, o problema da educação passou a ser importante pauta de discussão, abrindo o caminho para as grandes reformas educacionais. Com uma visão idealista, mas pragmática, Teixeira e seus colegas levantaram a bandeira da campanha pela educação pública nacional, iniciada formalmente pelo manifesto redigido por eles:

Esse documento público que teve a mais larga repercussão foi inspirado pela necessidade de precisar o conceito e os objetivos da nova política educacional e desenvolver um esforço metódico, rigorosamente animado por um critério superior e pontos de vista firmes, dando a todos os elementos filiados à nova corrente, as normas básicas e os princípios cardeais para avançarem com segurança e eficiência nos seus trabalhos (AZEVEDO et al., 2010, p. 24).

Com base nessas reflexões, Teixeira entende que a escola deve ser um ambiente social no qual o educando possa viver, não apenas preparar-se para viver futuramente. Dessa maneira, tal ambiente deve formar esse educando para resolver, de maneira autônoma, seus problemas presentes, em vez de focar na sua formação para um período imprevisível. Afinal, a educação, naturalmente, fará dele um indivíduo consciente e inteligente no futuro.

Com base nessa perspectiva, a Educação Progressiva tenta mostrar que o caráter teórico e fragmentado da educação tradicional não é producente aos olhos de quem está realmente preocupado com o aprendizado do indivíduo. Isso não quer dizer que o estudo não possa ter uma lógica, uma sequência ou uma organização. Contudo, esse modelo educacional propõe que essa organização seja realizada de maneira holística, partindo da ideia do todo para as partes. Teixeira exemplifica:

Para se ensinar a uma criança o que é um coelho ou um gato, é preciso mostrar-lhe primeiro o coelho ou o gato. A sua primeira noção será imprecisa, inadequada, mas não pode deixar de ser global. Não conseguimos tornar o conhecimento mais simples por the querermos ensinar primeiro o focinho, depois os pés, depois o rabo etc. À medida, entretanto, que o seu conhecimento progride, que ela começa a diferenciar as partes e estas passam assim a ter uma existência mental distinta do todo que é o coelho ou o gato, o seu conhecimento do animal se tornará mais minucioso, mais exato, mais completo e, podemos dizer, então, mais complexo (TEIXEIRA, 2000, p. 83).

Por esse viés, a Escola Progressiva representa a superação de um modelo de educação autoritário por uma educação que valoriza a experiência da criança. A ideia era que a nova escola se comportasse como um organismo vivo e que se abrisse a todos, mudando seu foco da classe na qual o aluno se encontrava para as aptidões e capacidades dele. Essa visão humanitária da educação estava ganhando valor, pois a escola passara a ser considerada de e para todos e a função educacional era vista como a capacidade de desenvolver ao máximo a função vital de cada indivíduo, apropriada a cada fase do desenvolvimento do ser humano.

Outra diferença da escola nova para a tradicional é que a primeira, além de estimular o aluno a buscar todos os recursos disponíveis para sua aprendizagem, valoriza o fator interesse do aluno. Explicam Azevedo et al.:

O que distingue da escola tradicional a escola nova não é, de fato, a predominância dos trabalhos de base manual e corporal, mas a presença, em todas as suas atividades, do fator psicobiológico do interesse, que é a primeira condição de uma atividade espontânea e o estímulo constante ao educando (criança, adolescente ou jovem) a buscar todos os recursos ao seu alcance, "graças à força de atração das necessidades profundamente sentidas” (2010, p. 50, aspas no original). 
Diante disso, a mudança da escola tradicional para a escola nova está diretamente ligada à transformação da sociedade e à nova concepção de homem moderno. A atual sociedade exige um cidadão com liberdade individual, entendendo-se liberdade como capacidade de orientar-se por sua autoridade interna. Em vista disso, faziam-se necessários programas e métodos educacionais diferentes, com um novo ideal de professor e de aluno.

Na visão de Teixeira, o único caminho para que essa mudança acontecesse era por meio da própria educação, aquela que se faz possível e propagada no âmbito da instituição chamada "escola", uma vez que cabe a ela adotar práticas interativas, participativas e democráticas, pelas quais todos os envolvidos na comunidade escolar possam interagir com as questões educacionais que acontecem dentro e fora da escola. Nascimento (2009) fortalece essa ideia quando reforça a importância da pluralidade democrática inserida nesse processo resultante da prática participativa. Dessa maneira, todos os sujeitos envolvidos podem contribuir ativamente com a produção de conhecimento e a formação de indivíduos para a vida comunitária.

De acordo com esse pressuposto, Geribello (1973) entende que Teixeira entrelaça as ideias de sociedade, indivíduo e escola ao crer que a última corporifica ideias, desejos e necessidades sociais, bem como prepara o ser humano para situações reais da vida, considerando o indivíduo e a sociedade uma unidade orgânica.

\section{A Escola Pública como Espaço de Participação Democrática}

Teixeira defendeu que o meio favorável para o desenvolvimento harmônico do homem é a educação como instituição formadora e essencialmente pública; ou seja, de e para todos, sendo essa responsabilidade do Estado. Dessa maneira, a formação do indivíduo não deveria ser função somente da família e das demais instituições que carregavam o papel social de educar, como a igreja. Com isso, a teoria da educação moderna passou a enxergar a importância da relação de família, escola e Estado no processo educacional do indivíduo.

Do mesmo modo, as questões técnicas e metodológicas da educação escolar estavam também sendo moldadas pelo ideal da escola ativa. Tal concepção não se associava à ideia de uniformidade; pelo contrário, baseava-se na ideia da multiplicidade. Um dos princípios da escola moderna era o da unidade nacional, permitindo que cada estado ou município tivesse liberdade e autonomia para desenvolver um trabalho educacional condizente com a cultura e a necessidade locais. Isso aponta que esse grupo de pensadores da educação lutou pela autonomia dos estados e dos municípios mediante o poder autocrático da União e defendeu que o Governo Federal ficasse com a responsabilidade de supervisionar os princípios da função educacional, além de oferecer estrutura e apoio nas dificuldades encontradas. Isso significa a descentralização do controle da educação. Segundo Azevedo et al.:

[...] a organização da educação brasileira unitária sobre a base e os princípios do Estado, no espírito da verdadeira comunidade popular e no cuidado da unidade nacional, não implica um centralismo estéril e odioso, ao qual se opõem as condições geográficas do país e a necessidade de adaptação crescente da escola aos interesses e às exigências regionais. Unidade não significa uniformidade. A unidade pressupõe multiplicidade (2010, p. 47).

Essa revisão de conceitos e fundamentos não significava um enfraquecimento da educação por sugerir mais autonomia no processo pedagógico. Pelo contrário, representava uma apropriação do então momento atual e uma adaptação ao modelo de sociedade contemporânea, visto que, na visão de Dewey (1979), a educação não tem um fim - ela é o seu próprio fim, em um processo contínuo de reconstrução e reorganização da experiência. 
Algumas meias reformas já haviam sido colocadas em prática. Contudo, não em sua totalidade. Essa era diferente: vinha para concretizar uma nova política educacional, preparando o caminho para a grande reforma, visto que nenhuma antes penetrou o âmago da questão. Mesmo assim, existia um receio de ficar só no papel. Infelizmente, as ideias propostas no Manifesto dos Pioneiros da Educação Nova (1932; AEVEDO et al., 2010) não se tornaram política pública graças aos anos autoritários que estavam sendo vividos com a ditadura.

O manifesto se esforçava para materializar os princípios da democracia como modo de vida de acordo com a teoria deweyana, a qual garante a liberdade de ser do indivíduo e o enxerga como uma pessoa com todas as suas potencialidades. Como disse Teixeira (2000), essa democracia, que preza o respeito pela personalidade humana, é a ideia mais profunda de uma sociedade transformada. No entanto, nenhuma sociedade se torna verdadeiramente democrática sem uma escola democrática, que alcance a todos de forma universal e obrigatória, sendo, portanto, pública - afinal, não se pode exigir a obrigatoriedade da educação sem que ela seja garantida gratuitamente.

Além disso, é importante destacar que o movimento da escola nova, o qual, a partir do século XIX, defendeu a escola pública como direito de todos e obrigação do Estado, influenciou a lei magna da educação nacional na atualidade. Assim sendo, a Lei de Diretrizes e Bases da Educação (BRASIL, 1996) define que a escola pública deve ser universal, gratuita, obrigatória, laica e de qualidade. Pública porque deve ser administrada pelo Estado. Universal pois deve fornecer a mesma educação básica para todos. Gratuita porque só assim todos teriam acesso às mesmas oportunidades intelectuais, operacionais e relacionais. Laica porque não privilegiaria nenhuma religião. De qualidade porque todo cidadão tem direito de desenvolver igualitariamente o hábito do pensamento reflexivo e suas habilidades individuais.

No entanto, a universalização do ensino ainda não conseguiu alcançar, no Brasil, o ideal desejado, mantendo, assim, a escolarização de qualidade abstrusa aos mais desfavorecidos. Teixeira bem colocou: "o seu programa, o seu currículo, mesmo na escola pública, era um programa e um currículo para privilegiados" (1871). Ademais, “[...] toda a democracia da escola pública consistiu em permitir ao 'pobre’ uma educação pela qual pudesse ele participar da elite” (TEIXEIRA, 1971, p. 29). Ainda em suas palavras:

[...] ora, a ideia de "educação comum", da escola pública americana ou da école unique francesa, não era nada disto. Não se cogitava de dar ao pobre a educação conveniente ao rico, mas, antes, de dar ao rico a educação conveniente ao pobre, pois a nova sociedade democrática não deveria distinguir, entre os indivíduos, os que precisavam dos que não precisavam de trabalhar, mas a todos queria educar para o trabalho, distribuindo-os pelas ocupações, conforme o mérito de cada um e não segundo a sua posição social ou riqueza (TEIXEIRA, 1971, p. 29).

Nesse sentido, acreditamos que é pela escola pública que o homem aumentará sua compreensão e passará a exigir e só aceitar o modelo de sociedade que o respeite como indivíduo membro de um todo; em que todos trabalhem e se responsabilizem pelas causas comuns. Teixeira, como nos lembra Geribello, ressaltou que é por meio da escola pública que todos os cidadãos podem alcançar igualdade política, intelectual e técnica, “[...] o que significa dar a todos oportunidades iguais de desenvolvimento e participação social" (GERIBELLO, 1973, p. 107). A escola que Teixeira propôs é aquela que, conforme exposto por Geribello (1973), faz-se instrumento da educação mais eficiente para a construção de uma sociedade democrática. Para tanto, Teixeira defendeu que a escola deve ser uma réplica da sociedade, organizando-se como conjunto de atividades reais do mundo, que vai além dos muros da escola. 
Desse modo, na teoria educacional anisiana, todo indivíduo é provido de inteligência, sendo, assim, capaz de contribuir com a sociedade à sua maneira, por meio da participação, o que lhe dignifica como ser social. Ademais, há necessidade de proporcionar a todos as condições de liberdade, inteligência e responsabilidade. A implantação de tal regime "não é algo que se possa promover por atos de vontade, nem pela simples não interferência governamental, mas o resultado de um sistema de educação estendido a todos e de extrema eficácia” (GERIBELLO, 1973, p. 105). Diante disso, Teixeira atestou que a escola deve proporcionar um ambiente de independência e liberdade em detrimento da adaptação e da reprodução das tarefas mecânicas praticadas pela escola tradicional.

Segundo Gohn, "Pateman [...], em seu livro Participação e Teoria Democrática, chama a atenção para o fato de que a participação gera atitudes de cooperação, integração e comprometimento com as decisões" (2014, p. 36). Para a autora, a participação tem um sentido educativo quando contribui com a formação de cidadãos voltados para os interesses comuns e para as questões sociais, sendo a ampliação dos espaços de atuação coletiva, como as escolas, uma forma de mostrar que o exercício da cidadania está para além da escolha dos governantes.

Ainda de acordo com Gohn (2014), a ideia é que a atuação popular aumente à medida que o indivíduo participa, pois ela se constitui de um processo de socialização; ou seja, quanto mais as pessoas agem coletivamente, mais elas disseminam essa prática e mais capacitadas se tornam para exercer os hábitos de cidadania. A educadora complementa: "em outras palavras, é participando que o indivíduo se habilita à participação, no sentido pleno da palavra, que inclui o fato de tomar parte e ter parte no contexto onde estão inseridos" (GOHN, 2014, p. 36). Sendo assim, é tomando parte nos assuntos e participando do processo de tomada de decisões, levando em consideração o interesse comum, que o cidadão pode perceber a importância da sua experiência nos processos participativos.

A escola, então, passa a ter um papel muito relevante, a ser vista como responsável pela formação do homem moderno e racional; ou seja, pela formação do cidadão. Portanto, constitui uma questão de interesse público, direito de todos e dever do Estado. Nessa perspectiva, o educador baiano lutou pela autonomia dos sistemas de ensino estaduais e municipais. Ele entendeu que a educação, por ser uma ciência humana e voltada para o indivíduo como ser social com suas potencialidades individuais, deve ser local. Por isso, a importância de descentralizar e encaminhar para os poderes municipais e estaduais a responsabilidade do sistema de ensino da sua região, de acordo com a cultura e as necessidades locais. Nascimento reforça:

A escola, pois, já não é, hoje, uma instituição para assegurar, apenas, como se pensava no século XIX, o "progresso", mas a instituição fundamental para garantir a estabilidade e a paz social e a própria sobrevivência da humanidade. Já não é, assim, uma instituição voluntária e benevolente, mas uma instituição obrigatória e necessária, sem a qual não subsistirão as condições de vida social, ordenada e tranquila (NASCIMENTO, 2009, p. 17, apud TEIXEIRA, 1999, p. 163).

Nascimento lembra que a proposta de uma escola pública caracterizada como minissociedade apresentada por Teixeira refere-se também à escola integral, não apenas em tempo cronológico, mas na sua essência, pois, segundo ele, “[...] visa à formação do cidadão autônomo, ético, participativo e engajado nas questões sociais" (NASCIMENTO, 2009, p. 26). A ideia de educação integral mostra que, em uma aula de geografia, o aluno não aprende apenas sobre planícies ou sistema solar; aprende também por meio da postura do professor diante de um desentendimento entre alunos, de seu posicionamento com relação a uma opinião diversa da sua, por meio da postura da gestão escolar acerca da coleta responsável de resíduos orgânicos e recicláveis e assim por diante. Essas aprendizagens estimulam os educandos a desenvolver atitudes para a vida comunitária. 
Figuerêdo (2015) ressalta que o pensamento de Teixeira era de uma escola que permitisse aos alunos vivenciar nela experiências condizentes com a realidade da comunidade na qual estavam inseridos. Explica a autora: "a preocupação em pôr em diálogo a escola, a vida social e o mundo do trabalho demonstra o projeto anisiano de superar a condição simplista das escolas da época por uma 'escola ativa' [...]" (FIGUERÊDO, 2015, p. 31). Nessa perspectiva, Nascimento (2009) relata que Teixeira defendeu a educação do homem não apenas para viver em uma sociedade democrática, mas também para construí-la. Portanto, precisamos de uma escola pública e universal, que forme um sujeito ativo e construtor do seu próprio conhecimento, em detrimento de um receptor de ideias prontas e impostas.

Importante relembrar que a sociedade moderna conseguiu ampliar algumas questões da universalização do ensino, pautadas nos ideais escolanovistas quando se emancipou do modelo de ensino intelectualista, que era para poucos, aproximando-se, então, da escola como necessidade e direito de todos. Algumas conquistas almejadas foram: a descentralização do sistema de ensino, levando a responsabilidade e a autonomia para as esferas municipais e estaduais; a elaboração de leis e regulamentações para a educação em nível nacional, abrangendo as instituições privadas e públicas; a profissionalização dos professores; maior acessibilidade da escola à classe mais desfavorecida; cursos técnicos para formação de profissões populares; a educação reflexiva e reconstrutiva da experiência; e a função social da escola, com seu papel de educação democrática, sobretudo com promoção, desenvolvimento e integração da sociedade.

\section{Considerações Finais}

O enfrentamento do conflito entre a função da escola pública, na condição de formadora de um povo soberano em uma sociedade democrática, e a visão mercadológica de preparação tecnicista, somados à ameaça de exclusão da formação humanística e à transmissão da cultura a fim de manter os privilégios das classes dominantes, levaram-nos a refletir acerca do papel da escola pública na sociedade. Para tratar desse assunto ainda atual, resgatamos o legado de Anísio Teixeira, que atuou na elaboração dos fins da escola pública como instituição responsável pela formação do indivíduo comprometido com os interesses comuns.

Almeida (1988) nos lembra de que um dos pilares básicos da prática pedagógica anisiana é o postulado da democracia e que, na sociedade neoliberal em que vivemos, esse postulado encontra limites claros para a sua concretização, dificultando, assim, a transformação escolar proposta. Ainda assim, Teixeira e todos aqueles que acreditam na sua teoria educacional defendem esse modelo de escola que forma o homem para a vida comunitária por meio de situações reais da vida social - que promovam igual condição para o despertar da inteligência e de habilidades individuais em prol do bem comum, as quais estimulam o pensamento reflexivo em busca da construção de novas formas de agir, bem como incentivam a liberdade individual do homem para se autorresponsabilizar. Além disso, colocam o professor ao lado do aluno para ajudá-lo nesse processo de libertação e investem na formação desse profissional permeado pelos ideais escolanovistas.

A democracia proposta nesse trabalho depende de um Estado capaz de repensar e desenvolver um processo que viabilize tais condições, colocando a educação escolar pública como uma das instituições responsáveis pela transformação da sociedade. Ao fazer isso, estamos responsabilizando-a pela formação do indivíduo, que fará a revolução pautada nos valores democráticos. Sendo assim, entendemos que a educação pública é o instrumento vital para a construção dessa sociedade. 
Desse modo, a escola pública mencionada é aquela que possibilita e estimula a pluralidade da participação social e considera o interesse do educando na prática pedagógica. Também preza pela reconstrução e pela reorganização das experiências como aprendizagem; preocupa-se com a capacidade relacional, intelectual e operacional dos alunos; e defende a educação como fim em si mesmo, uma vez que não está preocupada apenas com o futuro. Ela educa para o hoje, entendendo a educação, não como preparação para a vida, mas como a própria vida.

Para Teixeira, esse é o ideal de escola pública para a sociedade moderna, que se transforma de acordo com a necessidade, permitindo que a escola acompanhe essa transformação, reorganizando-se e reconstruindo-se de maneira reflexiva, crítica e democrática. Esse é o modelo que mostra como a educação escolar pode possibilitar a construção de uma sociedade democrática e desenvolvida, alcançando ainda a integração social proposta e almejada por Anísio Teixeira. Afinal, é com uma educação gratuita, universal e de qualidade que podemos fazer com que o homem perceba a importância da sua liberdade intelectual, do desenvolvimento das suas capacidades e do quanto elas se fortalecem quando pensadas e praticadas em conjunto. Portanto, a escola pública é a maneira de levar igualdade e liberdade intelectuais e políticas para todos, de modo que se tornem reflexivos, conscientes e participativos.

Diante disso, precisamos refletir acerca da contradição existente entre dois modelos de escola pública. Um deles é visto como forma de materializar o conhecimento intelectual, operacional e relacional a partir de bases democráticas; ou seja, o interesse comum de for mação como desenvolvimento das capacidades humanas para retribuição social. O outro modelo é aquele que, ironicamente, tem as elites dominantes no poder, haja vista que elas controlam o sistema econômico e o Estado, o qual, por essa razão, deixa de representar os interesses do público. Evidentemente, para a realização do ideal da escola para todos - ou seja, o primeiro modelo supracitado -, é necessário investimento em políticas públicas educacionais eficazes. Além disso, é fundamental enxergar essa escola como uma das obrigações prioritárias do governo vigente.

Exposta essa realidade, como conseguir investimento na escola pública? Quais movimentos sociais são necessários para efetivar o direito à educação? Não há, neste trabalho, resposta concreta. No entanto, sabemos que precisamos nos conscientizar e nos unir para chegarmos aos espaços que podem viabilizar o discurso democrático por meio da escola pública. Entendemos que um caminho para essa transformação é por meio dos órgãos oficiais da educação, pois, a partir deles, é possível realizar a construção disso em conjunto, nos níveis municipal, estadual e federal, utilizando os conselhos, os congressos e os fóruns da educação. É possível, também, propor e disponibilizar espaços abertos para a participação dos professores, dos alunos, das famílias e da comunidade, tendo força assim para perceber e impedir a participação tendenciosa de grandes grupos mercadológicos da rede educacional privada.

Outra saída pode ser a melhoria da formação dos profissionais da educação, com um viés mais crítico e político, bem como uma gestão democrática do ensino para que essa mentalidade chegue à base. A fim de que a massa popular encontre maneiras democráticas e eficazes de exigir do poder público a universalização do ensino igualitário, de qualidade, laico e gratuito, é necessário o entendimento do verdadeiro papel da educação sistematizada na sociedade atual. Nesse sentido, é fundamental valorizarmos a ciência do homem para os desenvolvimentos social e individual da humanidade. Tal entendimento deve ser representado pela valorização e pelo investimento nas ciências antropológicas, filosóficas e sociológicas; ou seja, na educação universitária, instituição essa responsável pelas ciências e pela formação dos profissionais da educação. 
Logo, para que a transformação democrática aconteça, propomos, ainda, a construção de políticas públicas educacionais que oportunizem e incentivem a participação popular como forma de desenvolver hábitos de cidadania, mesmo que, inicialmente, em esferas menores. Nesse sentido, defendemos a escola que deixa de ser uma instituição separada da realidade, sendo, ao contrário disso, o espaço de uma comunidade educativa que interage com a sociedade civil. Conforme destaca Gohn (2014), vivendo a prática da participação nos órgãos deliberativos da escola, os pais, os professores e os alunos vão aprendendo a se sentir responsáveis pelas decisões que os afetam em um âmbito mais amplo da sociedade. Também é válido lembrar que a escola é lugar de formação de habilidades para a participação na vida social, econômica e cultural.

Como via de mão dupla, por fim, defendemos que a democracia é capaz de assegurar a continuidade da educação por meio de uma organização pública sistematizada. Esse tipo de organização pode possibilitar a democratização da educação como prática reflexiva que gera processo de libertação e faz com que a sociedade se desenvolva e evolua coletivamente. Diante disso, trazemos os desenvolvimentos humano e social como perspectivas de integração social e de emancipação perante o domínio de um sistema não democrático.

\section{Contribuição dos Autores}

Problematização e Conceitualização: Magoga PM; Muraro DN; Metodologia: Magoga PM; Muraro DN; Análise: Magoga PM; Muraro DN; Redação: Magoga PM.

\section{Notas}

1. Filósofo norte-americano, nascido em Burlington, Vermont. Foi um dos precursores do pragmatismo, ao expor uma forma de pensar progressista. Dewey graduou-se em Artes e fez seu doutorado em Filosofia, seguindo carreira docente nesse campo.

2. Horace Mann foi um educador e político estadunidense com papel fundamental na criação da escola pública dos Estados Unidos.

3. Omer Buyse foi um engenheiro belga que se dedicou à problemática do ensino técnico-profissional. No começo da década de 1930, Buyse foi convidado pelo governo de Getúlio Vargas a realizar estudos sobre a organização e a instalação do ensino técnico-profissional no Brasil.

4. Para saber mais sobre a morte de Anísio Teixeira, indicamos a leitura da obra Breve História da Vida e Morte de Anísio Teixeira: Desmontada a Farsa da Queda no Fosso do Elevador, de João Augusto de Lima Rocha (2019).

5. Educador, político e sociólogo brasileiro. Foi autor do Manifesto dos Pioneiros da Educação Nova (1932; AZEVEDO et al., 2010) e do Manifesto dos Educadores (1959; AZEVEDO et al., 2010). Esses manifestos foram reunidos e publicados na Coleção Educadores, em 2010, em um projeto do Ministério da Educação (MEC) sobre expoentes da educação que aprofundaram as reflexões sobre as políticas educacionais no Brasil.

\section{Referências}

ALMEIDA, S. B. Escola Parque: Paradigma escolar (1947/1951). 1988. 156 f. Dissertação (Mestrado em Educação) - Faculdade de Educação, Universidade Federal da Bahia (UFBA), Salvador, 1988. 
AZEVEDO, F. et al. Manifesto dos pioneiros da Educação Nova (1932) e dos educadores (1959). Recife: MEC/Fundação Joaquim Nabuco/Editora Massangana, 2010. (Coleção Educadores.)

BRASIL. Lei n. 9.394, de 20 de dezembro de 1996. Estabelece as diretrizes e bases da educação nacional. Brasília, DF: Presidência da República, [1996]. Disponível em: http://www.planalto.gov.br/ccivil_03/leis/ 19394.htm. Acesso em: mar. 2020.

DEWEY, J. Vida e Educação. Tradução e estudo preliminar: Anísio Teixeira. 5. ed. São Paulo: Companhia Editora Nacional, 1959.

DEWEY, J. Democracia e Educação: Uma introdução para a Filosofia da Educação. Trad. Godofredo Rangel; Anísio Teixeira. 4. ed. São Paulo: Companhia Editora Nacional. 1979.

FIGUERÊDO, L. A. Educação integral na escola pública: Memórias de uma experiência pioneira na Bahia. 2015. 127 f. Dissertação (Mestrado em Educação) - Faculdade de Educação, Universidade Federal da Bahia (UFBA), Salvador, 2015.

GERIBELLO, W. P. Anísio Teixeira: Análise e sistematização de sua obra. 1973. 186 f. Tese (Doutorado em Filosofia da Educação) - Departamento de Educação, Pontifícia Universidade Católica de São Paulo (PUC-SP), São Paulo, 1973.

GOHN, M. G. Educação não formal, aprendizagens e saberes em processos participativos. Investigar em Educação - Revista da Sociedade Portuguesa de Ciências da Educação, $11^{\text {a }}$ série, n. 1, 2014. Disponível em: http://pages.ie.uminho.pt/inved/index.php/ie/article/view/4/4. Acesso em: 20 mar. 2020.

HENNING L. M. P. Anísio Teixeira - em destaque. In: EDUCERE - XII CONGRESSO NACIONAL DE EDUCAÇÃO: FORMAÇÃO DE PROFESSORES, COMPLEXIDADE E TRABALHO DOCENTE. 12., 2015, Curitiba. Anais [...]. Curitiba: Pontifícia Universidade Católica do Paraná (PUCPR), 2015, p. 20828-20838. Disponível em: https://educere.bruc.com.br/arquivo/pdf2015/18066_11282.pdf. Acesso em: 18 jan. 2020.

NASCIMENTO, G. R. O Centro Educacional Carneiro Ribeiro - Escola Parque: Simbologia de escola viva na comunidade do bairro da liberdade em Salvador-Bahia. 2009. 86 f. Dissertação (Mestrado Profissional em Teologia) - Faculdade Escola Superior de Teologia, São Leopoldo, 2009.

NUNES, C. Anísio Teixeira: A poesia da ação. Bragança Paulista: Edusf, 2000.

PIMENTA, R. Investigação, educação e democracia. Educação - História da Pedagogia, São Paulo, fascículo 6, p. 64-73, 15 dez. 2010.

ROCHA, J. A. L. Breve história da vida e morte de Anísio Teixeira: Desmontada a farsa da queda no fosso do elevador. Salvador: EDUFBA, 2019.

TEIXEIRA, A. Educação no Brasil. 2. ed. São Paulo: Companhia Editora Nacional, 1969.

TEIXEIRA, A. Educação não é privilégio. 3. ed. São Paulo: Companhia Editora Nacional, 1971.

TEIXEIRA, A. Educação no Brasil. 3. ed. Rio de Janeiro: UFRJ, 1999.

TEIXEIRA, A. Pequena introdução à Filosofia da Educação. Escola progressiva ou a transformação da escola. 6. ed. Rio de Janeiro: DP\&A, 2000.

TEIXEIRA, A. Educação é um direito. 4. ed. Rio de Janeiro: Editora UFRJ, 2009. 


\section{Sobre os Autores}

Darcísio Natal Muraro é graduado em Filosofia (1986) pela Pontifícia Universidade Católica do Paraná (PUCPR). Mestre em História e Filosofia da Educação (1988) pela Pontifícia Universidade Católica de São Paulo (PUC-SP) e doutor (2008) pela Faculdade de Educação da Universidade de São Paulo (USP) na linha "Filosofia da Educação". Temas de pesquisa: Pensamento Educacional Brasileiro; Ensino de Filosofia; Democracia e Educação.

Patrícia Melo Magoga é graduada em Pedagogia (2007) pela Universidade Estadual de Londrina (UEL). Pós-graduada, em nível de Especialização, em Gestão de Projetos e Programas Sociais (2014) pela Universidade Estácio de Sá. Mestre em Filosofia da Educação (2020) pelo Programa de Pós-graduação da UEL. Temas de pesquisa: Democracia; Educação; Filosofia da Educação; Experiência e Pensamento; Educação Escolar; Escola Pública; Desenvolvimento e Integração Social.

Recebido: 18 abr 2020

Aceito: 01 jul 2020 